\author{
Anna Krupińska \\ Mgr inż. \\ Instytut Techniczny Wojsk Lotniczych \\ anna.krupinska@itwl.pl
}

DOI: 10.35117/A_ENG_18_09_05

\title{
Selected problems of material testing of damaged compressor disks made of titanium alloys
}

\begin{abstract}
In many cases, performing material tests of damages in aviation structure elements requires analysing similar problems in specific construction elements. This article describes two similar cases of damages in compressor disks made of titanium alloys. In the article examined elements are presented, as well as nature of their damages. Moreover, the article discusses applied test methods and how tests were performed. Included in the article test results analysis leads to identification of the causes of the damages.
\end{abstract}

Keywords: Material testing; Damages; Compressor blades; Titanium alloys

\section{Introduction}

Every component of aircraft structures (aircraft or ground equipment necessary for their operation) damaged during operation is subject to tests to determine the cause of this damage. This is mainly due to the need to maintain the efficiency of aviation techniques and the need to ensure flight safety. Analysis of the results of these tests allows determining whether the tested damage is accidental, one-time or whether there are factors that may contribute to the occurrence of similar damage during the operation of analogous elements of aircraft structures. By carrying out material tests of these elements, the causes of similar damage to identical elements are often analyzed. This paper presents test results for two cases of analogous damage to compressor discs made of titanium alloy.

\section{The object of research - a fourth stage disc of a low pressure compressor}

Figure 1 shows a schematic diagram of the low-pressure compressor (fan) of the RD-33 engine, on which the fourth-degree disc is marked with an arrow. As mentioned earlier in this article, the results of tests of two cases of damage to the secondary stage IV disk of the RD-33 low-pressure compressor will be presented. From the analyzed documentation [2], [3] it appears that on the RD-33 engines three types of rotors (components) of the fan were mounted. In each of them, the Manufacturer used other construction solutions. In the case of both fans, where the IV grade discs were damaged, type II rotors were mounted. According to the technical documentation [3], the total hourly allowance of the type II fan assembly is not less than 1200 hours. Based on the metrics of the fans in question, it was found that they have increased hourly resources from $1200 \mathrm{~h}$ to $1600 \mathrm{~h}$ - changes were made at the engine manufacturer's plants. Damage to these discs occurred after 1323 and less than 1325 working hours, respectively. For order purposes, cases of damage to the fan's 4th stage disk were marked as "1" and "2", according to the chronology of the damage occurrence. A full description of the tests of all damaged elements of RD-33 engines, on which the described fourth-degree shields were used, is presented in the Protocols of the Aviation Materials Laboratory of the Air Force Institute of Technology No. 1/36/2014 and 2/36/2014. 

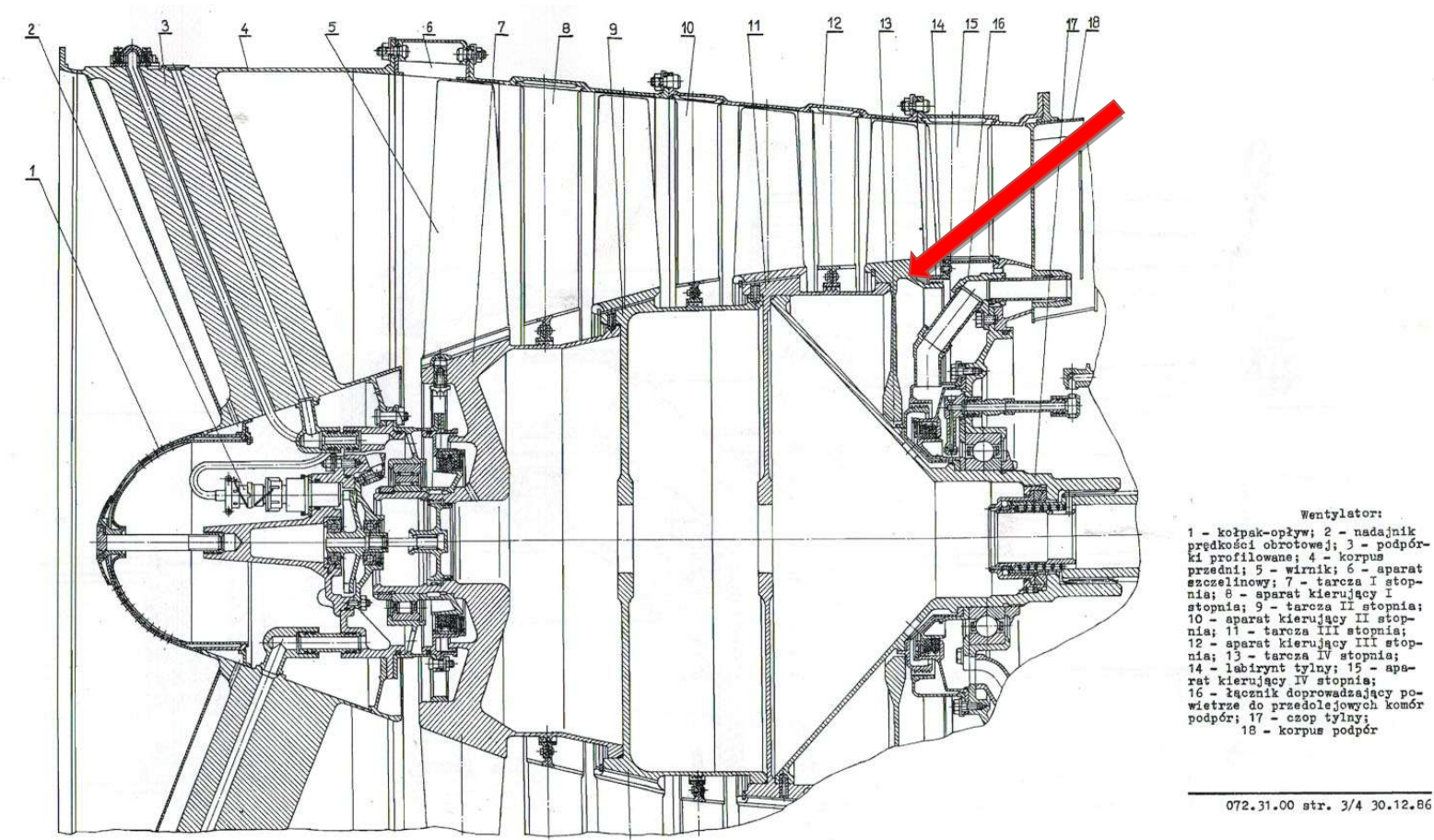

1. The scheme of construction of a low pressure compressor (fan) of the RD-33 engine with a marked fourth degree disc

\section{Results of macroscopic tests - identification of damage to IV level discs of low pressure compressors}

Macroscopic examinations were carried out with an unarmed eye, and their results were recorded using a CANON Power Shot G5 camera 6934113437 and a Nikon SMZ $800 \mathrm{nr}$ 1015651 stereoscopic microscope. The numbering of the blade sockets of both compressor stage IV discs was introduced during the commissioning dismantling of both engines. Figure 2 shows the engine fan impeller RD-33 with a defective grade IV disc, marked as "1" in the test delivery state. In contrast, figure 3 shows the stage IV fan disc of the RD-33 step, also marked as "2" in the test delivery state. Detailed results of these tests are provided in Table 1. The main damage to both tested discs of the IV stage of the fan rotor of RD-33 engines was the cracking of the discs in the blade seat No. 4, in the case of the disk marked " 1 " and the blade socket No. 26, in the case of the disk, marked "2". They are cracks throughout. The cracking of the disk marked "1" propagated along the radius of the disc from the side of the leading edge and the trailing edge, and the disc " 2 " along the radius of the disc from the side of the air intake and from the side of the high-pressure compressor. As a result of macroscopic examinations, tests performed by computed tomography (performed in the Aircraft Engine Institute of the Air Force Institute of Technology) and non-destructive examinations carried out by visual, penetrant and eddy current methods (carried out in the Non-destructive Testing Laboratory of the Aircraft Flight Department of the Military Technical Institute The dimensions of the disk crack "1" were determined for: length $38 \mathrm{~mm}$, the opening was 0.8 $\mathrm{mm}$, and the disk "2" for length $35 \mathrm{~mm}$, opening about $1 \mathrm{~mm}$. In addition, as a result of the above-mentioned tests, there were no internal or external defects in the discs that could initiate the cracks in question. In the blade No. 4 , where the crack "1" occurs, the lack of a working spatula was noted. On the edge of the lock of the fourth-degree disc in the blade seat No. 4, in the upper part of it, there were two chipping, defects of the shield material, which arose from the side of the spine. The crush lengths are respectively: $14 \mathrm{~mm}$ and $4.5 \mathrm{~mm}$. Crushing was probably caused by impacts on the surface of the loose lock (due to the cracking of the blade) of the blade No. 4 . 


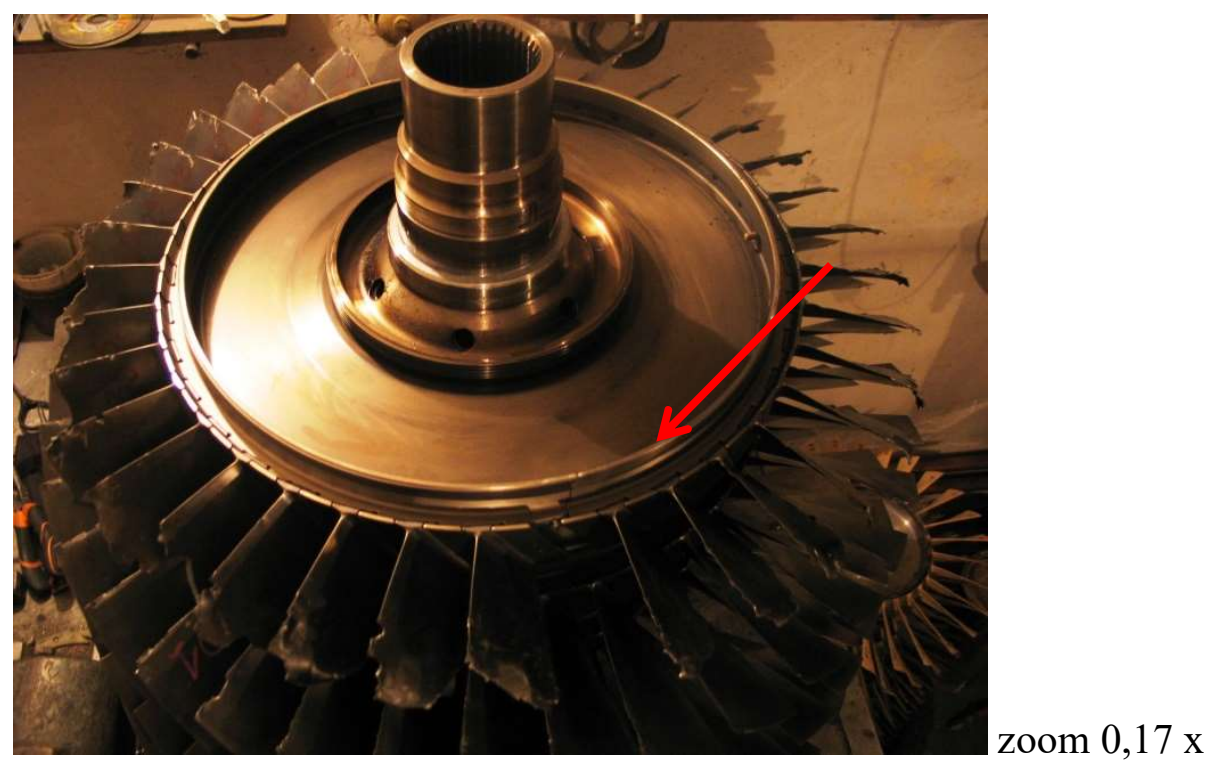

2. The fan impeller of the RD-33 engine with a damaged IV grade disc marked as "1" in the state of delivery for testing, the figure shows a visible crack of the 4th degree disc

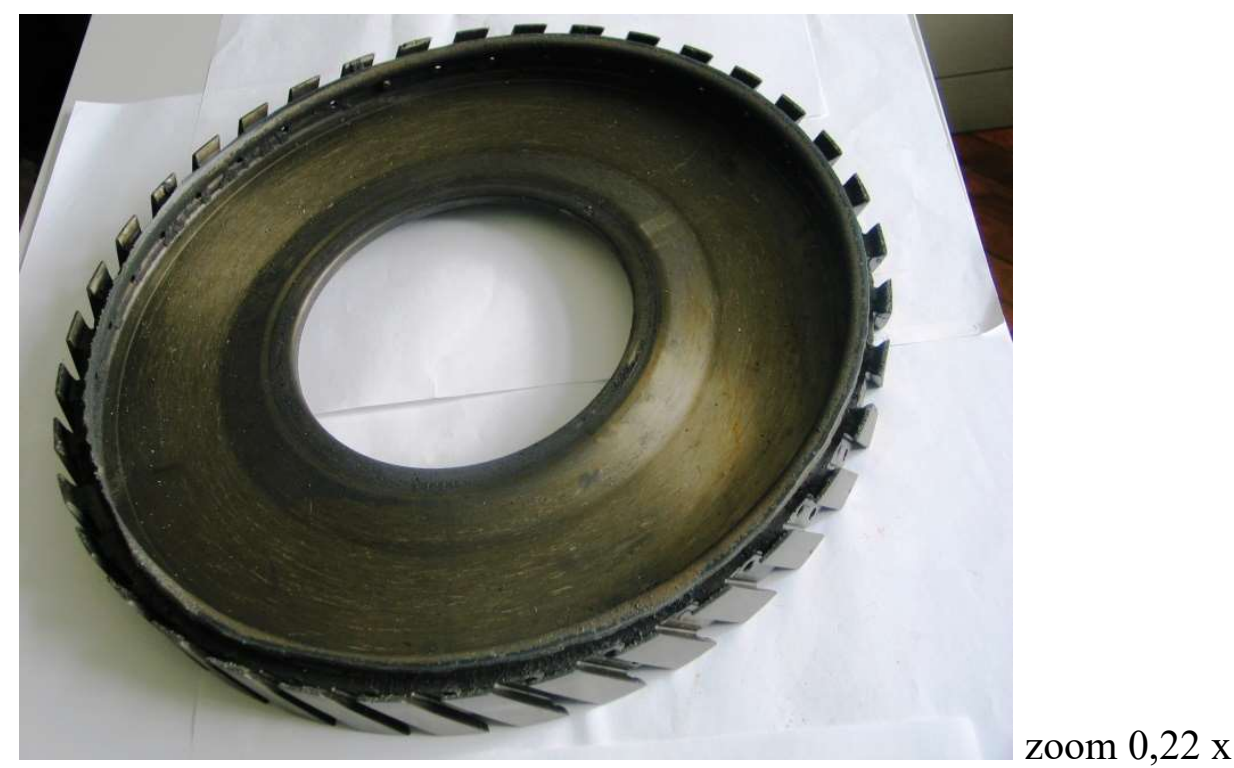

3. The fourth-degree fan of the RD-33 engine fan is marked as " 2 " in the state of delivery for testing

In addition, as a result of macroscopic and defectoscopic tests, in the case of the "1" disk, 14 cracks of 2.5 to $8 \mathrm{~mm}$ were detected in the area of the shoulder of the shoulder blades, from 2.5 to $8 \mathrm{~mm}$ respectively, and 2 fault indications were identified. However, in the case of the "2" disc, 26 cracks were detected with dimensions from 1.5 to $8 \mathrm{~mm}$ respectively. Three of them, the cracks in the nests of the No. 1, 19 and 24 blades are cracks throughout.

Tab. 1. Macroscopic description of the condition of both tested discs of the IV stage of the RD-33 engine fan

\begin{tabular}{|c|c|}
\hline Element & Description of the condition of the item under examination \\
\hline 4th stage low- & $\begin{array}{c}\text { Figure 3. A break in the cross-section of the disc, extending over a length } \\
\text { pressure compressor } \\
\text { of about 35 mm (counting from the blade collar), propagating from the slot } \\
\text { the blade No. } 4 \text { along the radius of the blade from the side of the leading } \\
\text { the vane socket No. }\end{array}$ \\
\begin{tabular}{c} 
edge and the trailing edge of the blades. Zoom 2,3 x. \\
\hline
\end{tabular}
\end{tabular}




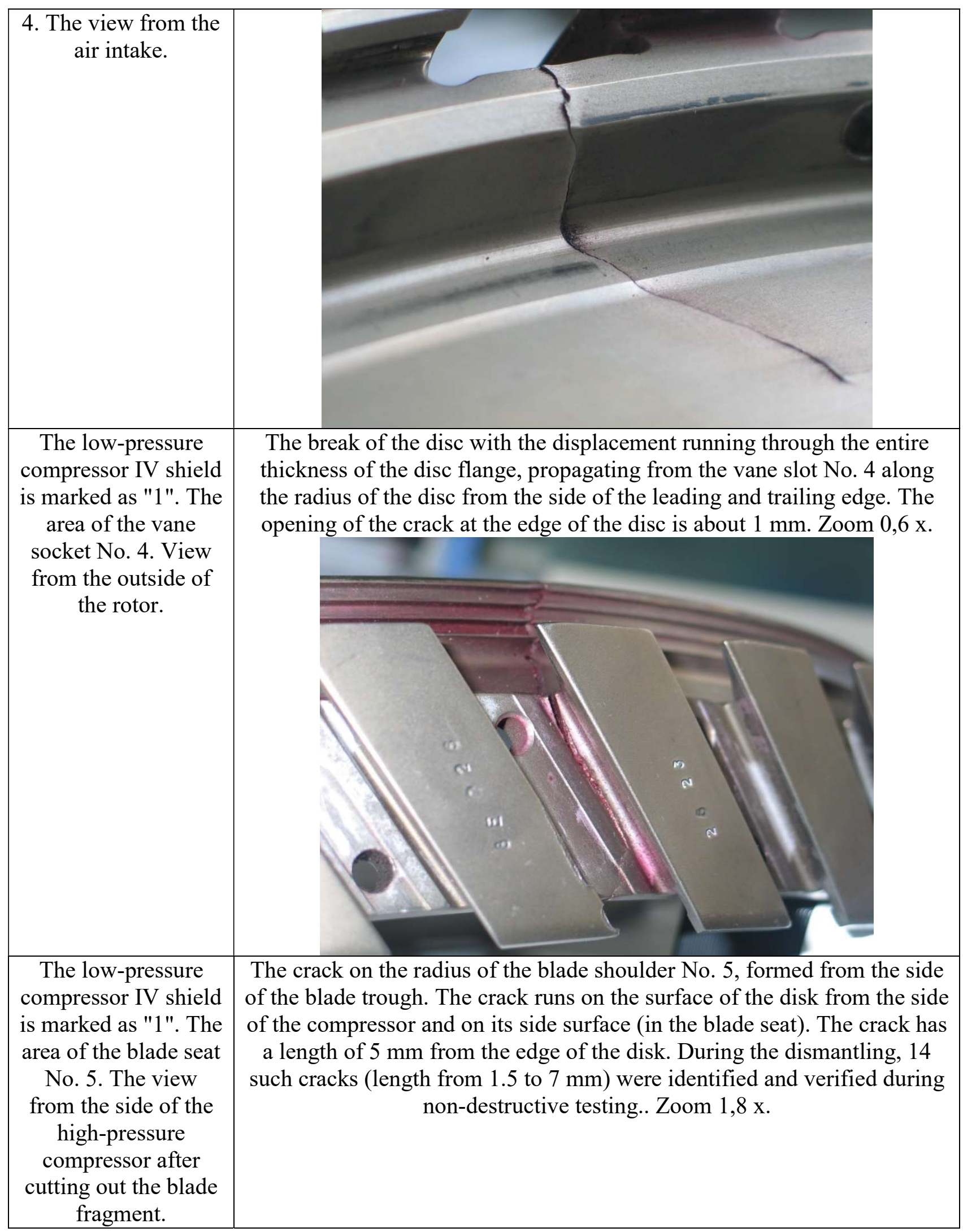




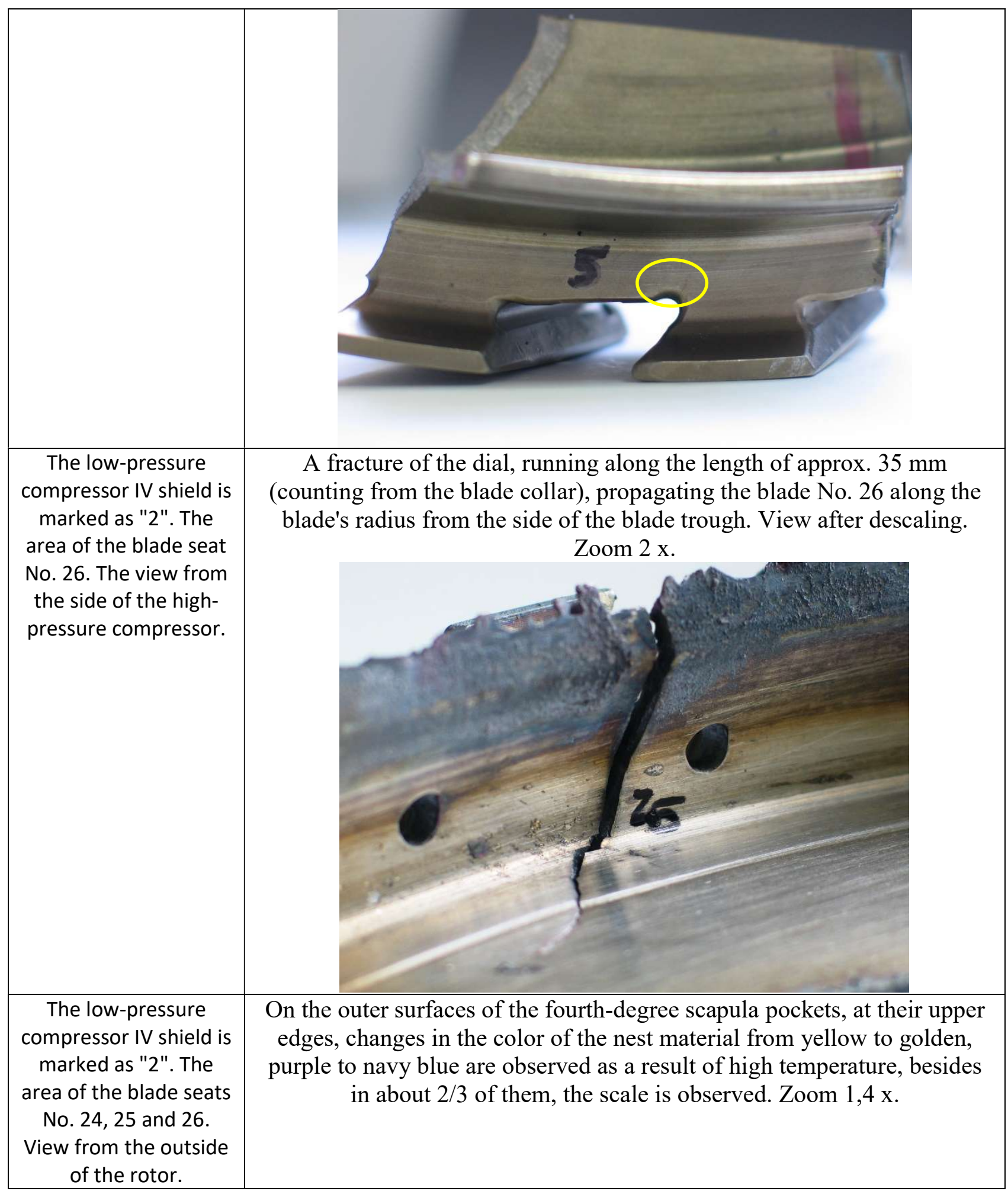




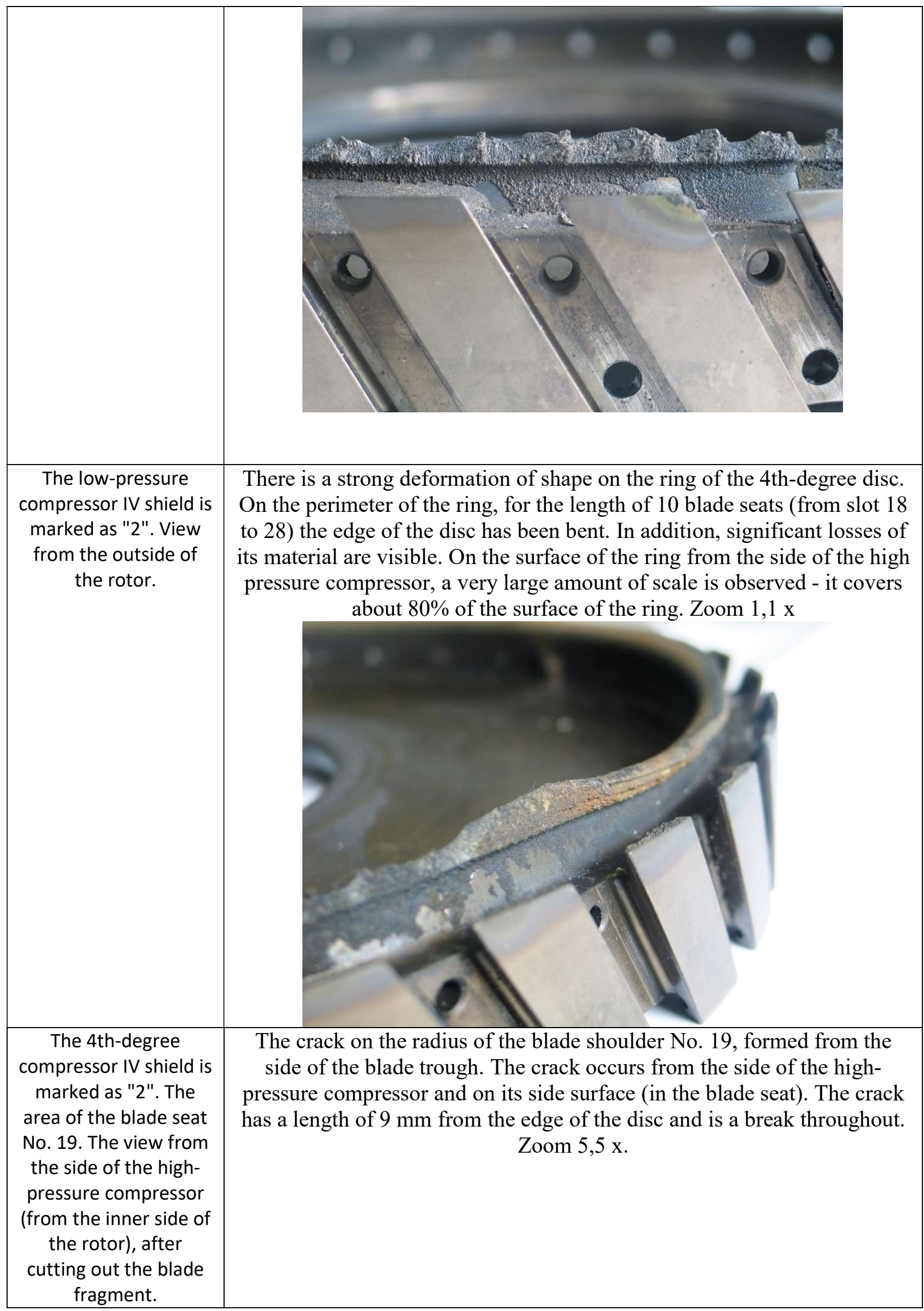




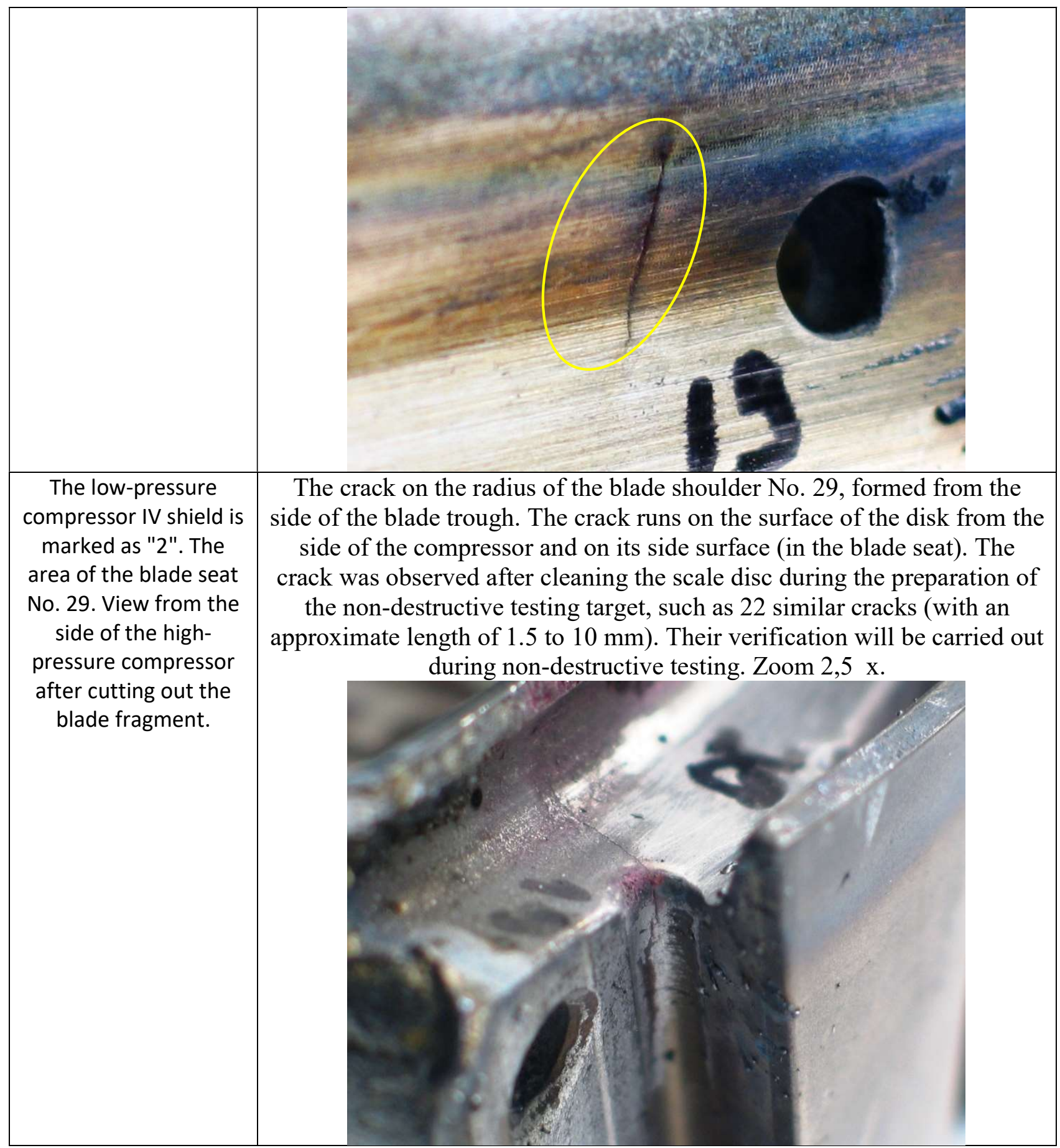

\section{Macroscopic fractal research}

The fractographic tests were conducted with an unarmed eye, and their results were recorded with the CANON Power Shot G5 camera No. 6934113437 and with the Nikon SMZ 800 stereomicroscope No. 1015651. In the case of the "1" disk, two fractures of the fan rotor disk IV were tested: cracks from the vane no. 4 and cracks from the vane socket No. 5 (randomly selected from among 14 cracks detected in macroscopic and non-destructive tests). In the case of the "2" shield, the following five scrap crack fractures were tested: cracks from the blade seat No. 26, 24, 29, 30 and 31 cracks from the blade seat No. 5 (randomly selected from among 14 cracks detected in macroscopic and non-destructive tests).

Figure 4 shows the macro construction of the fourth stage disc scrap in the blade seat No. 4 in the area marked as "1". During the tests, three scrap zones with a characteristic 
design and color were found. The first of them is a region with a characteristic shell shape at the outer surface of the shield - the focal zone. The area of scrap in this zone is golden-yellow. The second one is a zone of crack growth characterized by small surface roughness and its gray color. The construction of scrap in both above-mentioned zones shows macroscopic features of fatigue cracking. The third zone is the dugout (zone with the largest surface roughness). The change of color in the focal zone of this region - "1" of the shield scrap "1" in the blade seat No. 4 and the construction of this scrap area suggest that this scrap fragment originated earlier than the others, where no color changes were observed. Figure 5 shows the macro construction of the fourth-degree shield scrap marked as "2" in the blade seat No. 26 ". During the tests, three scrap zones with a characteristic structure were found. The first of them is a region with a characteristic shell shape at the outer surface of the shield flange - the focal zone. The second one is a zone of crack growth characterized by small surface roughness. The construction of scrap in both above-mentioned zones shows macroscopic features of fatigue cracking. The third zone is the dugout (zone with the largest surface roughness).

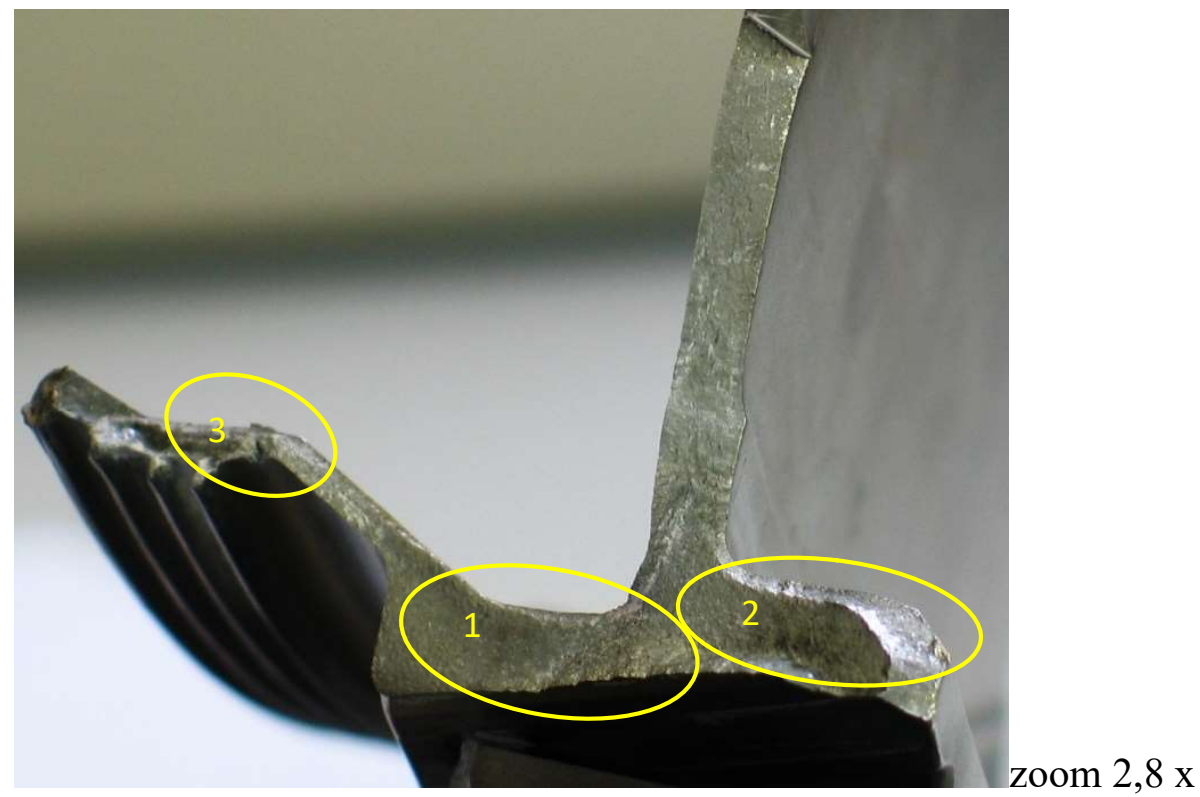

4. Macro construction scrap of the 4th-degree disc marked as "1" in the blade seat No. 4 with marked characteristic areas of scrap description in the text

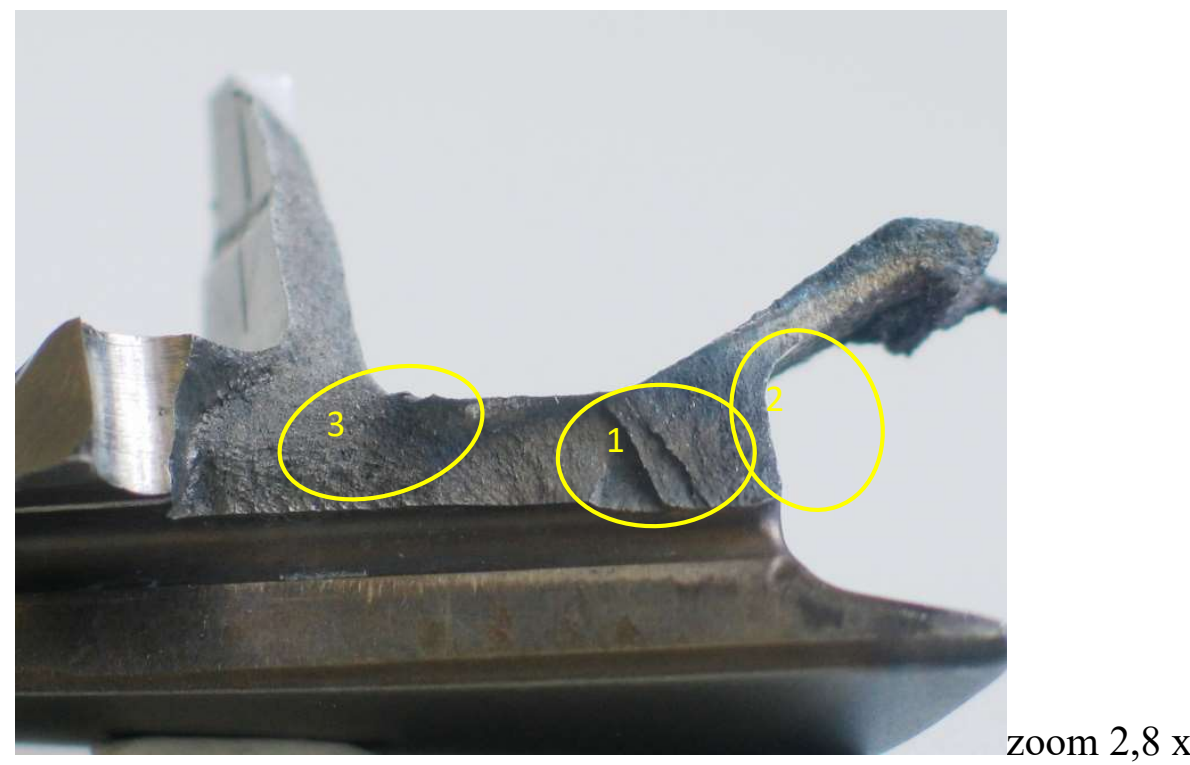


5. Macro construction scrap of the fourth-degree disc marked as " 2 " in the blade seat No. 26 with marked characteristic areas of scrap description in the text

The source of loads of the rotor fan wheel IV of the RD-33 motor in the discussed area is circumferential stresses resulting from the method of mounting the disc ("push-in") and vibration of the blade in the disc slot. In addition, the area described is the area of the notch bottom. As a result of the conducted tests, it is estimated that the fatigue centers in the scrap regions marked as "1" were the initiation places for cracking both discussed IV discs in blade seat No. 4 for disc "1" and blade seat 26 for disc "2". The cracks of the discussed IV rotor discs started the process of destroying the RD-33 engines, on which they worked.

The macro construction scrap of the "1" shield in the No. 5 blade seat did not exhibit fatigue cracking features. However, the results of electron microscopic microbalance of scrap (made at the Laboratory of Materials Design of Aviation Structures accredited at the Polish Center for Accreditation - certificate No. AB-431) carried out to determine the fracture mechanisms of both tested grade IV discs showed that it was a fatigue crack. In the case of disk "2", the construction of scrap metal from the blade seat No. 29 was subjected to research. Two scrap zones with a characteristic structure: a fault zone and a dove zone were tested. The results of the analysis of the conducted electromicroscopic tests confirm the fatigued character of 1/10 of scrap. Microbial scrap indicates the crack propagation under the influence of cyclic loads with a relatively high frequency and small amplitude - vibrations.

\section{Metallographic research}

In order to evaluate the quality and verification of the materials of both examined discs IV compressor low pressure and verification of the results of macroscopic examinations, metallographic examinations were performed. The tests were performed using a metallographic microscope Nikon Eclipse MA 200 No. 730042.

Observation of the structure was carried out on metalized metallographic cuts prepared for this purpose. The observations show that the structure of the material of both examined discs IV stage of the fan rotor in the core is a two-phase, oriented $\alpha+\beta$ plate and globularplate structure with various degrees of dispersion of $\alpha$ phase plates (see Fig. 6). The fan rotor IV wheels are made of two-phase titanium alloy WT9, belonging to the group of martensitic alloys $\alpha+\beta$. WT9 alloy is a heat-resistant alloy designed for plastic working, based on the TiAl-Mo Zr-Si system [1]. The structure shown in Figure 6 is suitable for the WT9 titanium alloy.

Figure 7 shows the structure of the shield material IV marked as "1" in the blade seat No. 4 , in the vicinity of the scrap metal marked as "1", in the bump zone, at the edge of the sample. During the research, no defects or structural heterogeneities were found that could contribute to the destruction of the target. In the case of disc "2", there were also no defects and structural non-homogeneities of the material in the blade seat No. 26, in the area of scrap metal. 


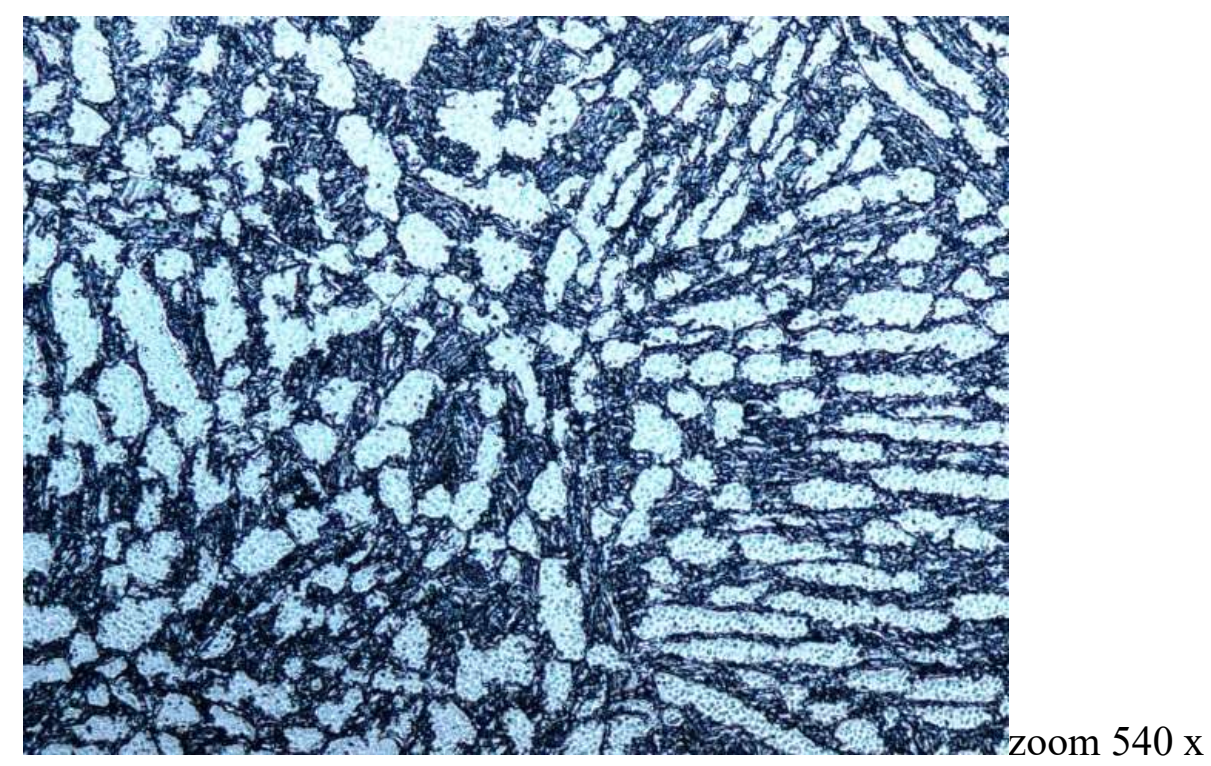

6. Grated 1/36 / 14-2 grinding - axial section through the low-pressure compressor stage IV disc designated as "1", away from the crack initiation points and the damage observed. Image of material microstructure, characteristic for both tested disks for areas located far from the damage.

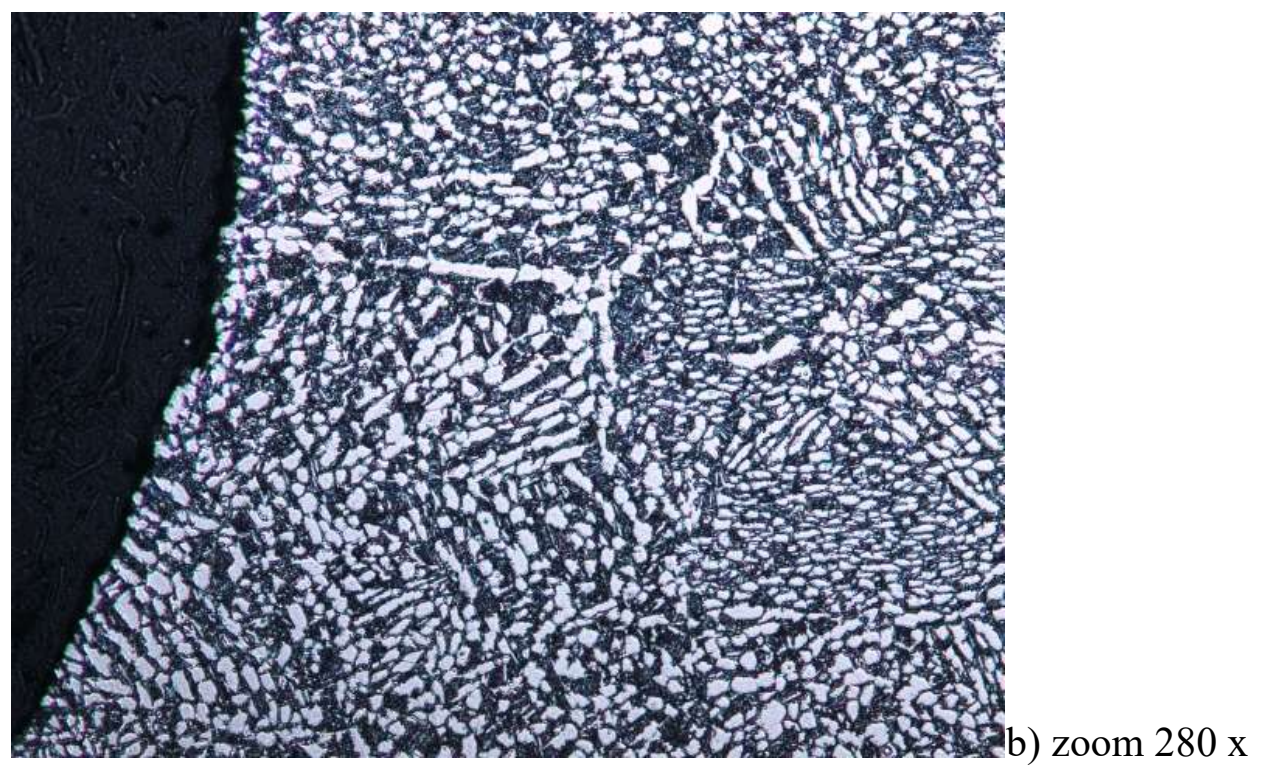

7. Grinded cut 1/36/14-5 - cross-section perpendicular to the surface of scrap in the region marked as "1", in slot No. 4 of the shield "1". Image of the microstructure in the nasal zone characteristic for both examined discs.

\section{Hardness measurements}

Hardness measurements were taken on pickled and not hit joints as a complement to microstructure tests to verify the material of both 4th-degree discs. Hardness measurements were made at the Materials Engineering Laboratory of Aviation Structures accredited by the Polish Center for Accreditation (accreditation certificate No.: AB 431). Rotor fan IV wheels are made of WT9 titanium alloy. As a result of hardness measurements carried out, no significant differences in hardness were found in the cores of the tested cross-sections of both discs. The average hardness of the target material " $1 "$ in the core is $358 \pm 9 \mathrm{HV} \mathrm{10,} \mathrm{which} \mathrm{is}$ the approximate calculation corresponds to the tensile strength $-\mathrm{R}_{\mathrm{m}}$ from 1130 to $1200 \mathrm{MPa}$ [4]. On the other hand, the dial "2" is $350 \pm 5 \mathrm{HV} 10$, which is the approximate calculation 
corresponds to the strength $\mathrm{R}_{\mathrm{m}}$ from 1130 to $1150 \mathrm{MPa}$ [4]. According to the requirements specified in the literature [1], the tensile strength for WT9 titanium alloy after thermomechanical treatment should be $\mathrm{R}_{\mathrm{m}}$ minimum $1100 \mathrm{MPa}$, which means that the material properties of the tested disc are in accordance with literature data. In groundwater areas, at the edges of samples, the average hardness of the target material "1" increases to $391 \pm 12 \mathrm{HV} 0.2$ (except for sample 1/36 / 14-4 - cross-section perpendicular to the surface of scrap in the region marked as "2", in the nest No. 4 4th stage low pressure compressor disc, where no increase in hardness of the material in the pressure zone is noticed, the average hardness value for this sample is $345 \pm 6 \mathrm{HV} \mathrm{0,2).} \mathrm{However,} \mathrm{for} \mathrm{the} \mathrm{"2"} \mathrm{dial,} \mathrm{it} \mathrm{increases} \mathrm{to} 375 \pm 10 \mathrm{HV} \mathrm{0,2.}$ The observed, slight increase in the hardness of the material in the scrap zones is a natural, unquestionable phenomenon.

\section{Summary of test results}

The primary damage to both tested rotor IV degree discs of the RD-33 engine fans was their fatigue cracking, initiated in the area of the blade seat No. 4 in the case of the shield marked "1" and in the area of the blade seat No. 26 in the case of the disk marked " 2 ".

All other defects of the tested disks are of a secondary nature.

No material defects or inhomogeneities in the structure and properties of the material were found that could promote the initiation and development of fatigue cracks in the tested disks.

Damage to the disc "1" occurred after 1323 hours of engine operation, while the disc "2" after less than 1325. It is estimated that probably both discs completely exhausted the reserve of fatigue life.

\section{Source materials}

[1] Bylica A., Sieniawski J., Tytan i jego stopy, , Państwowe Wydawnictwo Naukowe, Warszawa 1985 r.

[2] Dokumentacja 88-TR-12 „Demontaż, remont i montaż wirnika wentylatora”.

[3] Dokumentacja techniczna nr TT-285 "Instrukcja resursów zespołów i silnika RD-33”.

[4] Mały Poradnik Mechanika, tom 1, Nauki Matematyczno-Fizyczne, Materiałoznawstwo, Wydawnictwo Naukowo-Techniczne, Warszawa 1994 r. 